\title{
متطلبات تحقيق المنظمة البارعة بـالجامعات المصرية
}

\author{
اعداد \\ أ.د / قُتحي أحمد عبدالحليه \\ الأستاذ المتفرغ بقسم التربية المقارنة والإدارة التعليمية \\ كلية التربية بقنا - جامعة جنوب الوادي \\ Fathy.haleem72@yahoo.com

\section{أ/ ابتسام محمد عبد الالاه محمد} \\ باحثة لدرجة دكتوراه الفلسفة في التربية \\ تخصص إدارة تعليمية \\ كلية التربية بقنا- جامعة جنوب الوادي \\ ibtsammohmed@yahoo.com \\ أ. د/ أشرف محمود أحمد \\ أستاذ التربية المقارنة والإدارة التعليمية \\ كلية التربية بالبحرالأحمر -جامعة جنوب الوادي \\ Ashraf.mahmoud56@yahoo.com

$$
\begin{aligned}
& \text { أ.م. د/ محمد صبري الأذصاري } \\
& \text { أستاذ التربية المقارنة والإدارة التعليمية المساعد } \\
& \text { كلية التربية بقنا- جامعة جنوب الوادي }
\end{aligned}
$$ \\ Alansary_83@yahoo.com
}




\section{متطلبات تحقيق المنظمة البارعة بـالجامعات المصرية}

\section{أ. أد/ فتحي أحمد عبدالحليي}

الأستاذ المتفرغ بقسم التربية المقارنة والإدارة التعليمية

كلية التربية بقنا - جامعة جنوب الوادي

Fathy.haleem72@yahoo.com

\section{أ أبسام محمد عبد الزلاه محمدل}

باحثة لدرجة دكتوراه الفلسفة في التربية تخصص إدارة تعليمية

كلية التربية بقنا- جامعة جنوب الوادي

ibtsammohmed@yahoo.com

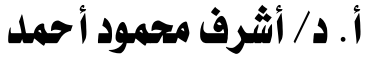

أستاذ التربية المقارنة والإدارة التعليمية

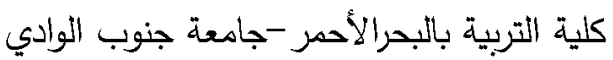
Ashraf.mahmoud56@yahoo.com

أ.م. د/ محمد صبري الأذصاري

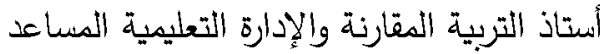

كلية التربية بقنا- جامعة جنوب الوادي

Alansary_83@yahoo.com

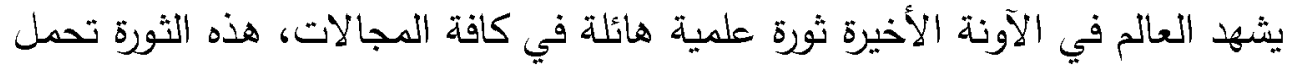

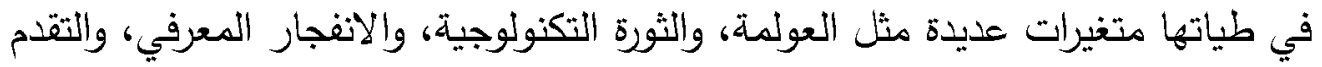

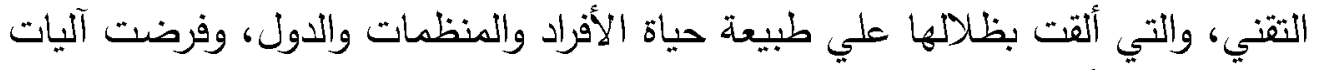

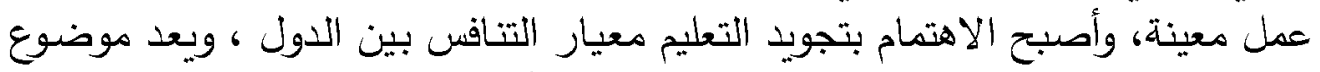

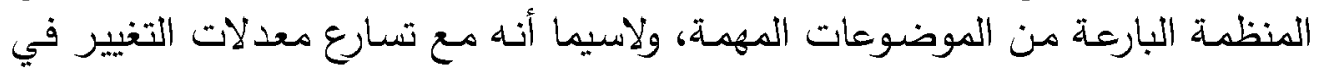

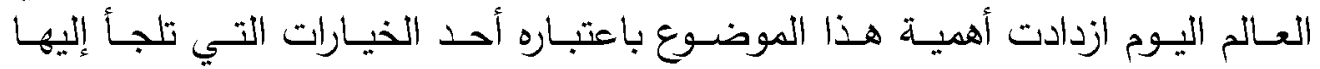

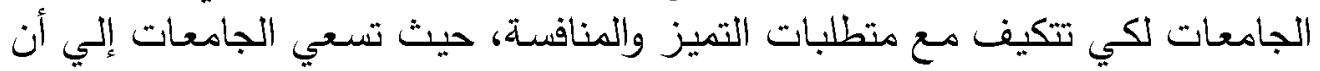

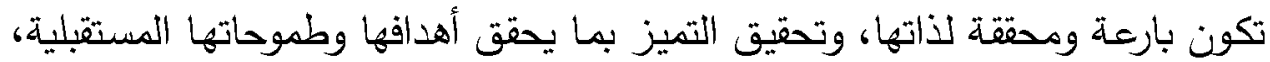

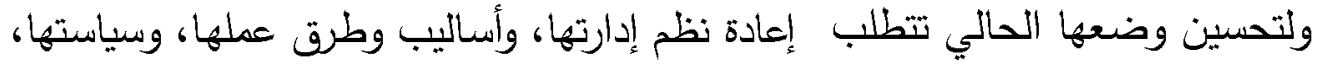

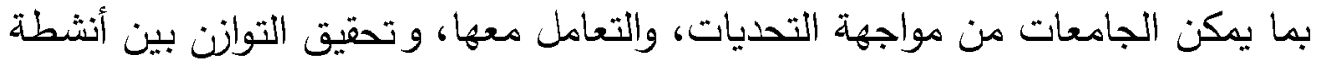

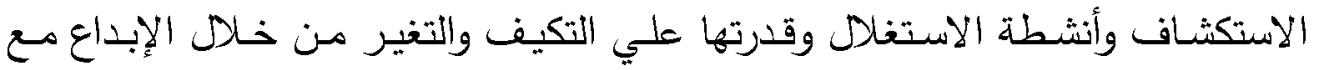

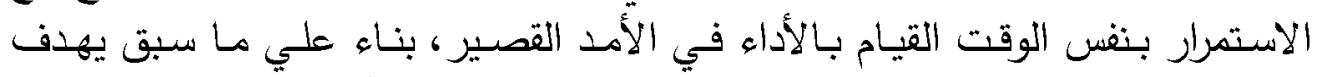

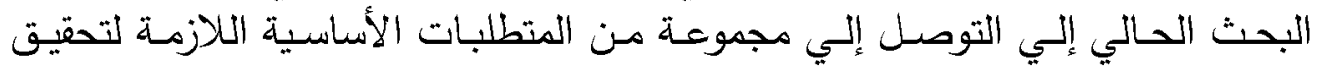

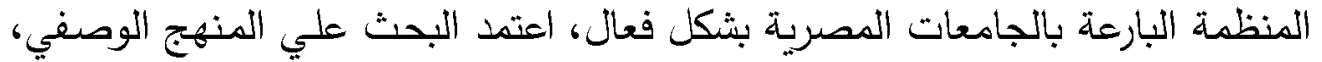

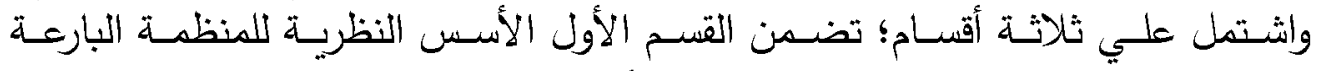

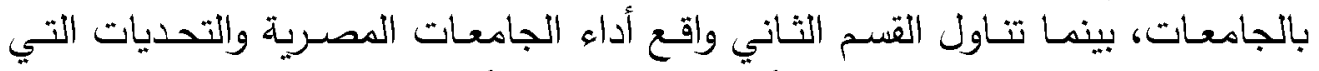

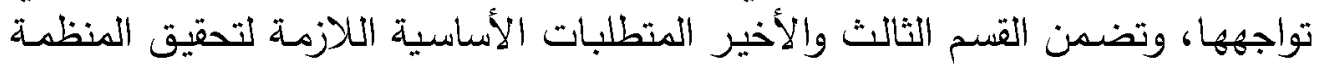

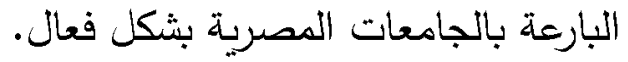
الـ الـ ات الـ ف احدة المات المنظمة البارعة - الجامعات المصرية . 


\section{Requirements for Achieving Ambidextrous Organization in Egyptian Universities}

Dr. Ashraf Mahmoud Ahmed

Professor of comparative Education and Educational Administration

Faculty of Education-

South Valley University

Ashraf.mahmoud56@yahoo.
Dr. Fathey Ahmed Abdelhaleem

Professor of comparative Education and Educational Administration

Faculty of Education-

South Valley University

Fathy.haleem72@yahoo.com
Dr. Mohamed Sabry Elansary

Ass.Professor in comparative Education and Educational Administration

Faculty of Education-

South Valley University

Alansary_83@yahoo.com
Ebtisam Mohamed Abdellah Mohamed

A researcher for the Degree

of Doctor Philology in Education

Specialization "Educational Management"

South Valley University

ibtsammohmed@yahoo.com

\section{Abstract:}

The world is witnessing a huge scientific revolution recently in all fields, this revolution carries with it many variables such as globalization, technological revolution, knowledge explosion, and technical progress, which cast a shadow on the nature of the lives of individuals, organizations and countries, and imposed certain mechanisms of work, and interest in improving The criterion of competition between countries. To improve its current situation, it requires the restoration of its management systems, its methods and methods of work, and its policy, in order to enable universities to face challenges and deal with them, and to achieve a balance between exploration and exploitation activities and their ability to adapt and change through creativity while continuing to perform in the short term.Based on the foregoing, The Current research aims to arrive at a set of basic requirements needed to achieve Ambidextrous Organization in Egyptian Universities. The research relied on the descriptive Methodology, and it implied following sections: the first one included the theoretical bases of Ambidextrous Organization in Universities, While the second one included the reality of achieving Ambidextrous Organization in Egyptian Universities and the challenges facing Egyptian Universities, the third and final one included the requirements achieve Ambidextrous Organization in Egyptian Universities effectively.

KeyWords: Ambidextrous Organization - Egyptian Universities. 
تعد الجامعة قاطرة للتقدم العلمي والتنمية في المجتمعات المعاصرة؛ حيث تسهم في بناء الكوادر البشرية القادرة علي إنتاج المعرفة، وتطويرها، ونشرها، وتوظيفها في معالجة مشكلات المجتمع وقضاياه، وهذا ما دعا إلي ضرورة الاهتمام بتطوير أداء الجامعات، بما يمكنها من تحقيق رؤيتها ورسالتها، والأهداف المرجوة منها. وتبرز الجامعات كأحد أهم المنظمات التي تقوم بذور فعال في تطور المجتمعات وتقدمها، وأنها السبيل لتجاوز التخلف واللحاق بركب التطور ، وتعد الجامعة قاطرة للتقدم العلمي والتتمية في المجتمعات المعاصرة؛ حيث تسهم في بناء الكوادر البشرية القادرة علي إنتاج المعرفة، وتطويرها، وهذا ما دعا إلي ضرورة تطوير أداء الجامعات، بما يمكنها من تحقيق رؤيتها، ورسالتها، والأهداف المرجوة منها. وأصبحت الجامعة في عصر العولمة تسعي إلي التميز في أدائها، من خلال تبني سياسات واستراتيجيات ناجحة ومتميزة في إدارة وتتظيم أعمالها، ولتحقيق التوازن بين الجامعات وقدرتها علي المنافسة ظهر ما يسمي بالمنظمة البارعة فهي بحاجة إلي مسـاهمة جميع مـن فيها لتحقيق أهدافها، وتحسين الإنتاجيـة، وإعـادة هيكلتهـا وتنظيمها بما يتناسب مع مجريات العصر لتحقيق المنظمة البارعة. ترجع البدايات الأولي وتنطلق فكرة المنظمة البارعة من موضوع أساسي في أديبات الإدارة يطلق عليه تتاقض التعلم (Learning Paradox)، وارتبط هذا المفهوم في البداية بإدارة الابتكار ومنذ ذلك الحين تم توسيع هذا المفهوم إلي مجالات إدارية أخري مثل التعلم التنظيمي، والذي تتطلق قاعدته المعرفية من أفكار نظرية التعلم التنظيمي التي تعود جذورها التاريخية إلي علم النفس، ويعد دنكان (1976,168 (Duncan, 
وظهرت فكرة المنظمة البارعة لأول مرة كرد فعل للتحول من العمل الروتيني إلي بيئة تنافسية ديناميكية من قبل المنظمات وأظهر العديد من الباحثين أن لايهر القدرة التنظيمية علي اتباع أمرين مختلفين في نفس الوقت مثل كفاءة التصنيع والمرونة، والتمايز والتكلفة المنخفضة وتحديد المواقع الاستراتيجية، التكامل العالمي والاستجابة المحلية (Zacher \& Wilden, 2014,815).

وتعرف المنظمة البارعة بأنها (O'Reilly \& Tushman (2010) هي التي تحقق نجاحا كبيرا في الواقع العملي من خلا استغلال الحاضر واستشراف المستقبل، وتتميز بقدرتها علي الاستكشاف وابتكار هياكل وعمليات جديدة. وذُكر بأنها انغماس المنظمة بالأشطة الاستكشافية والأشطة الاستغلالية (التوسيعية) بشكل متزامن في أداء متطلبات عملهم داخل المؤسسات (صالح عبد الرضا، عامر علي، r ب. ب، ( ). وتثير أيضا إ لي قدرة المنظمة علي تحقيق التوازن بين أنشطة الاستكثاف مثل البحث والتجريب وأخذ المخاطر والبحث عن حلول بديلة، وأنشطة الاستغلال مثل التنفيذ وتجنب المخاطر وتقليل التباين في السلوك (BirkinShaw \& Gupta, 2013). وبالتالي يمكن تحديدها كمنظمة قادرة علي استكثاف بيئتها في وقت واحد واستغلال الفرص الناشئة أو بعبارة أخري منظمة قادرة علي متابعة العمليات الحالية للتكيف مع البيئة التنافسية المتغيرة، حيث يشمل الاستكثاف قدرة الجامعة علي البحث والمخاطرة، الاستغلال هو قدرة الجامعة علي التنفيذ والإنتاج وتحسين وتنفيذ المهام. ويمكن القول بأن الجامعات في أمس الحاجة لوجود المنظمة البارعة لقدرتها علي تجويد العمل، وتحقيق المزايا التتافية، بعدما أثارت العديد من الدراسات مثل دراسة Coleman)(إلي أهمية وجود المنظمة البارعة ودورها في صنع رؤية قوية 
لفريقها وتهيئة بيئة تعاونية تسمح بالمخاطرة وتثجع علي توليد الأفكار الإبداعية

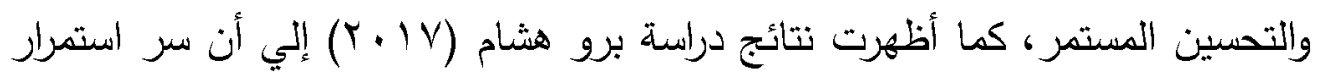

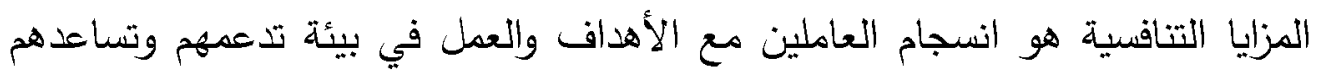

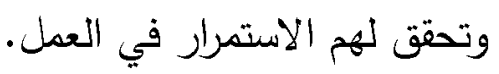

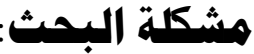

بالرغم من الجهود التي تبذلها الإدارة بالجامعات، إلا أنها مازالت بحاجة إلي مزيد من التجديد والتطوير بمـا يتلاءم مـع الثورة المعلوماتية والتكنولوجيـة والعولمـة، والانفجار المعرفي، والثورة الرقمية، وينطلب ذلك وجود أعضاء علي درجة عالية من المهارة، وقـادرة علي التكيف مـع التغيرات المستمرة، ووجود العديـ من المشكلات والتحديات التي تواجه الجامعات، حيث توصلت دراسة عبير همام (10 • ب) إلي اتسام الجامعات بوجود المركزيـة الإدارية المغرطة، تعقد الهياكل التنظيمية، نمطية وتقليدية التخصصات والبرامج، وهذا ما أثـارت إليه دراسة وفاء عياد (T ب r) حيث المركزية في الإدارة، والتعقيد والتسلسل، والتنظيم الهزمس، والتروتين الـوظيفي، وقلـة استخدام

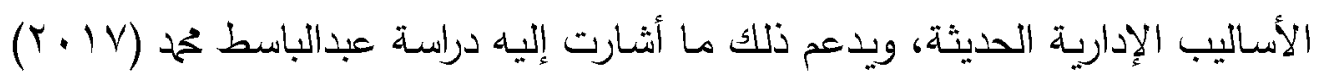
حيث أثار إلي مركزية السلطة، وتعدد اللوائح والقوانين والإجراءات الروتينية اليومية.

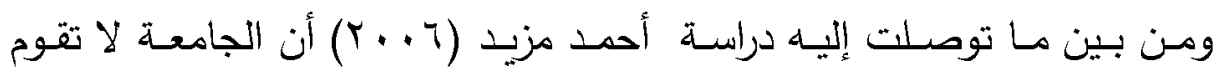

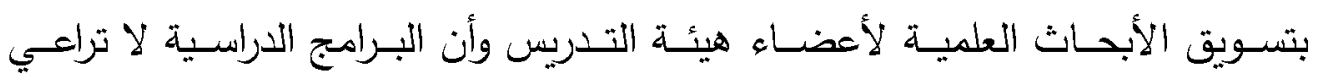

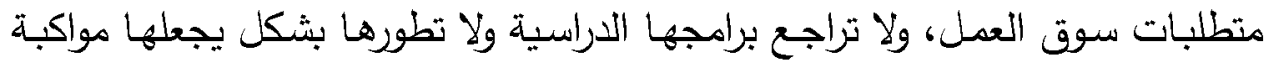

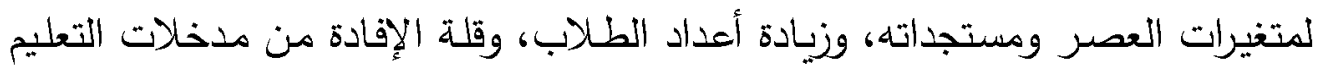

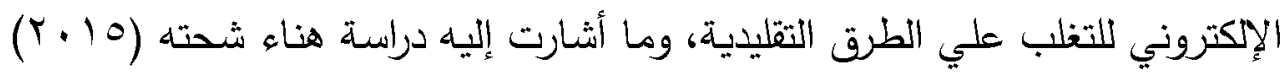
إلي الفجوة الهائلة بين الواقع الفعلي للجامعات والمستوي المطلوب الوصون الثران إليه، الأمر 
الذي يؤدي إلي تراجع الجامعات المصرية الذي يحقق لها ميزتها التنافسية بين مثيلاتها من الجامعات.

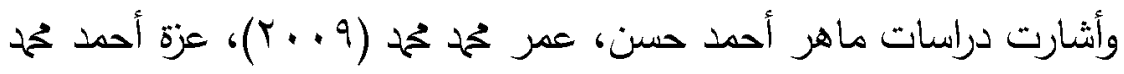
الحسيني(Y ( ا ب)، إلي ضعف قدرة الجامعات المصرية علي مواجهة المنافسة القادمة من الجامعات الأجنبية التي تتسم بالحركة السربعة وقدرتها علي التكيف مع متطلبات البيئة المحيطة، الفجوة الهائلة بين الواقع الفعلي لمؤسسات التعليم الجامعي والمستوي

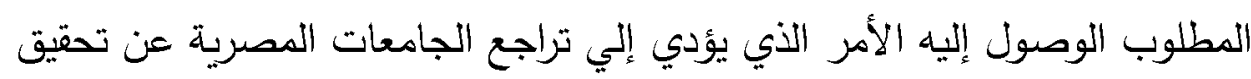
الريادة والتميز بين مثيلاتها من الجامعات، اقتصار ما تقدمه الجامعات المصرية لهرية لمجتمعها علي مجرد مشروعات دعائية، وانعزالها عن مشاكل البيئة المحيطة بها. ولمـا كانت مصر تسعي في الفترك الحالية إلب النهوض بمستوي جامعتها، وتخريج الكوادر المؤهلة والقادرة علي مواكبة المنطلبات العالمية، وزيـادة قدرة الجامعات

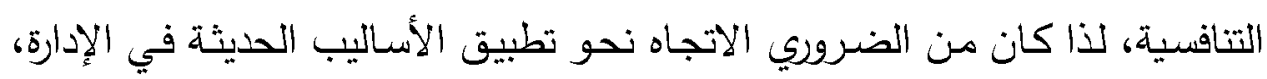

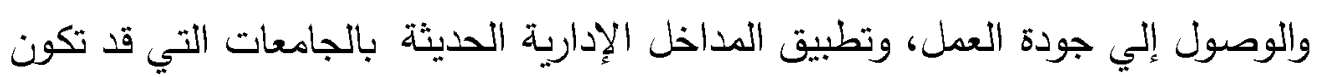

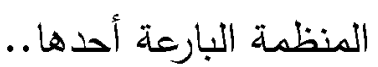

\section{وعلي ذلك، تتحدد هشكلة البحث في الأسئلة الآتية:}

ا - ما الأسس النظرية المرتبطة بالمنظمة البارعة بالجامعات؟ r- ما واقع تحقيق المنظمة البارعة بالجامعات المصرية؟ وما التحديات التي تواجهها؟ r- ما متطلبات تحقيق المنظمة البارعة بالجامعات المصرية؟

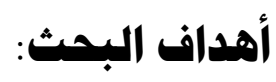
يهدف البحث إلي ما يلي: 
ا ـ التعرف علي الأسس النظرية المرتبطة بالمنظمة البارعة بالجامعات.

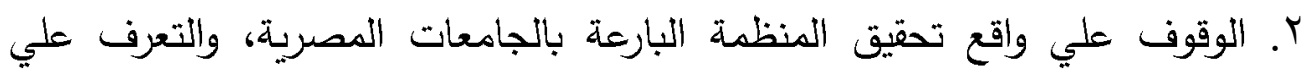

$$
\text { التحديات التي تواجهها. }
$$

r. التوصل إلي متطلبات تحقيق المنظمة البارعة بالجامعات المصرية.

\section{أهميهة البحث:}

$$
\text { تتضتح أهمية البحث فيما يلي: }
$$

1 - أنه يتزامن مع الجهود المبذولة من الجامعات في الارتقاء بجودة أدائها وخدماتها من أجل الوصول إلي التميز ، وبما يضمن لها ميزتها التنافسية.

r- يمكن أن تسهم هذه الدراسة في إغناء المكتبة العربية بموضوع حديث قد يحظى باهتمام الباحثين، ويعد هذا البحث نقطة الانطلاق لدراسات أخري في المنظمة

$$
\text { البارعة في مناطق ومجتمعات أخري. }
$$

r- من المنتظر أن يستقيذ من نتائج الدراسة المسئولون عن الإدارة بالجامعة، بالإضافة إلي المعنيين من أعضاء هيئة التدريس ومعاونيهم وطلاب وعاملين وأعضاء المجتمع المحلي.

ع- قد تنبه المسئولين من واضعي السياسات ومتخذي القرار في الجامعات إلي تحقيق المنظمة البارعة بالجامعات المصرية لمواكبة التطورات وتحسين الأداء وتحقيق المزايا التنافسية، والتخلص من المشكلات التي تواجهها المنظومة الجامعية.

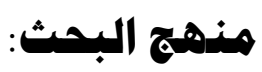

في ضوه طبيعة مشكلة البحث الحالي وأهدافه، فإنه يسير وفقا لخطوات المنهج الوصفي؛ حيث يتضمن وصفا وتحليلاً لطبيعة المنظمة البارعة بالجامعات، وواقع 
الجامعات المصرية والتحديات التي تواجهها، وذلك من أجل التوصل إلي مجموعة من المتطلبات الأساسية اللازمة لتحقيق المنظمة البارعة بالجامعات المصرية بشكل فعال. بناء علي ما سبق، يسير الجزه التالي من البحث وفقا لثلاثة أقسام، يدور القسم الأول حول الأسس النظرية للمنظمة البارعة بالجامعات، بينما يتناول القسم الثاني واقع الجامعات المصرية والتحديات التي تواجهها، أما القسم الثالث والأخير فسيتضمن مجموعة من المتطلبات الأساسية لتحقيق المنظمة البارعة بالجامعات المصرية، وفيما يلي عرض تفصيلي لتلك الأقسام الثلاثة علي النحو الآتي:

\section{أولاً: المنظمة البارعة بالباهمعات:}

يتضمن هذا الجزه التأصيل النظري للمنظمة البارعة بالجامعات، من هيث طبيعة

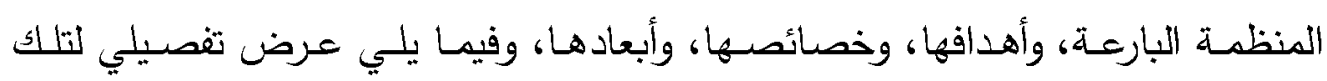
المحاور علي النحو الآتي: - ملي:

\section{ا أ وبيعة المنظمة الباروة بالباهمات:}

ينطوي عالم المستقبل علي تحديات تفوق التحديات التي يشهدها عالمنا الحاضر كما ونوعا، إذ أن عملية ملاحقة التغيرات والتطورات في بيئة الأعمال وما تتطلب من ضرورة تخطيط عمليات التكيف المستمرة للجامعات، ولتحقيق النجاح والبقاء والديمومة والربحية، ولتكون أفضل من منافسيها فهي بحاجة إلي أن تعمل علي تحسين نفسها وتغييرها باستمرار .

ومع ازدياد ديناميكية البيئة العالمية، تواجه الجامعات حالة دن الانقطاع والتغيرات السريعة، والعالم تحول من الابتكار المدمر إلي الابتكار الخلاق، والمنافسة 
العالمية الثديدة، والتعديلات في الأنظمة الحكومية، والتغيرات في هياكل الصناعة، فهي دائما ب حاجة إلي أن تكون بارعة وتعمل علي استغلال ما هو متاح لها من فرص، والبحث عن فرص جديدة، بالثكل الذي يساعدها علي التكيف مع البيئة التي تعمل ضمنها البقاء في سوقها المستهدف وتحقيق أهدافها Beer, Voelpel, Leibold \&) . Tekie,2005, 446) وهذه التحديات التي أفرزتها التغيرات السريعة والمتلاحقة دعت إلي إصلاح أداء الجامعات، وتعظيم قدرتها علي المنافسة بالسعي المستمر لتطوير جودة أدائها، وتحقيق التميز فيما تقدمه من خدمة تعليمية وبحثية ومجتمعية، بما يمكنها من التعامل مع هذه الأوضاع الجديدة بكفاءة، نظرا للاور البارز للجامعات في تحقيق التنمية الشاملة، وتحسين الموقف التناقسي لها بين الدول. وترجع البدايات الأولي وتنطلق فكرة المنظمة البارعة من موضوع أساسي في أديبات الإدارة يطلق عليه تناقض التعلم (Learning Paradox)، وارتبط هذا المفهوم في البداية بإدارة الابتكار ومنذ ذلك الحين تم توسيع هذا المفهوم إلي مجالات إدارية أخري مثل التعلم التنظيمي، والذي تنطلق قاعدته المعرفية من أفكار نظرية التعلم التظيمي التي تعود جذورها التاريخية إلي علم النفس، ويعد دنكان (1976,168 (Duncan, للمنظمات التي تريد اتباع نهجين مختلفين نحو الابتكار، الأول أن تبدأ تطوير أنشطة مبتكرة أي استكثاف الابتكار، والثاني تتفيذ أنشطة مبتكرة أي استغلال الابتكار، وفسر أنها تتبع إما الاستكشاف أو الاستغلال ولكن علي المدي الطويل تتبع كلا النهجين، واقترح أيضا أن المنظمات تحل هذا التناقض بالمجيء بالبراعة، والذي أشار إلي قدرة المنظمة علي أن تدير أعمالها اليومية بكفاءة مع القدرة علي التكيف والتأقلم مع 
التغيرات البيئية، وجاء للتأكيد إلي حاجة المنظمات إلي اعتماد هياكل تنظيمية مزدوجة لغرض تطبيق وتنفيذ الإبداعات الحالية وتقديم إبداعات جديدة. ويعد بيترز ووترمان أول من اقترح أن المنظمات المتميزة تمتلك مجموعات متنوعة من الشخصيات المتتاقضة وهما الاستكشاف والاستغلال، واقترحوا أن المنظمات تحتاج إلي أن تكون متساوية في الطلب في تنفيذ الأنشطة الحالية واستكثاف الفرص المستقبلية من أجل ضمان المدي البعيد، وفي بداية التسعينات من القرن الماضي جاء البروفسور جيمس مارس(James March,1991,71) لتطوير وتوليذ اهتمام أكبر بهذا المفهوم وخاصة في أواخر القن العشرين وأوائل القن الحادي والعشرين حيث يعد أول محفز للمجال حيث نشر مقالة أساسية بعنوان " الاستكثاف والاستغلال في التعلم التنظيمي وتعزيز مفهوم البراعة التنظيمية والتكيف مع المنظمة" مع التركيز علي العديد من الاحتمالات الجديدة (الاستكثاف والاستغلال) وأول من توحد مفهومي الاستكثاف والاستغلال حيث قام بتفسيرهما كمتعمين مختلفين حيث يشير الاستكثاف إلي البحث والاختلاف، بينما يشير الاستغلال إلي التنقيح والكفاءة والاختيار والتنفيذ وهو ما يتطلب من المنظمات ضرورة توزيع المنظمات اهتماماتها ومواردها بين هذين التوجهين بالثكل الأي يضمن لها النجاح والاستمرار . وظهرت فكرة المنظمة البارعة لأول مرة كرد فعل للتحول من العمل الروتيني إلبي بيئة تنافسية ديناميكية من قبل المنظمات وأظهر العديد من الباحثين أن لايهم القدرة التنظيمية علي اتباع أمرين مختلفين في نفس الوقت مثل كفاءة التصنيع والمرونة، والتمايز والتكلفة المنخفضة وتحديد المواقع الاستراتيجية، التكامل العالمي والاستجابة المحلية (Zacher \& Wilden, (2014,815). وبالتالي يمكن تحديدها كمنظمة قادرة علي استكثاف بيئتها في وقت واحد واستغلال الفرص الناشئة أو بعبارة أخري منظمة قادرة علي متابعة العمليات الحالية 
للتكيف مع البيئة التنافسية المتغيرة، حيث يثمل الاستكثاف قدرة الجامعة علي البحث والمخاطرة، الاستغلال هو قدرة الجامعة علي التنفيذ والإنتاج وتحسين وتنفيذ المهام et, أن (Rialti al.,2018,1093) واقترح) (Mc Donough \& Leifer, ,1983, 730) وحدات العمل تستخدم هياكل متعددة للتعامل مع الطوارئ المتعددة التي تواجههم، وأن التحدي الرئيسي هو تحقيق الت وازن بين كمية التثابه وكمية الاختلاف والارتباط بين

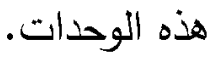

مما سبق يمكن القول بأن الجامعة كمنظمة بارعة تضم مفهومين مختلفين وهما الاستكثاف والاستغلال أو الاستثمار حيث يتطرق الاستكثاف إلي ابتكار الأنثطة أما الاستغلال فإنه يشير إلي تتفيذ الأنشطة وهذا يتطلب الاتقان والقدرة والمواءمة وتحقيق التوانن بين الاستكثاف والاستغلال لتحقيق ميزة تتافسية وهذا يؤدي في النهاية إلي تحقيق كلا النهجين للوصول إلي جامعة بارعة. r. أهداف المنظمة البارعة بالجاهمعات: تتمثل أهداف المنظمة البارعة في ما يلي:

.(Raisch \& Birkinshaw,2008) (Deem, et al., 2007) قدرة الجامعة كمنظمة بارعة علي تحقيق التوازن بين أنثطة الاستكثاف مثل البحث والمخاطرة، وأنشطة الاستغلال مثل التنفيذ والإنتاج وتحسين المهام. اعتماد هياكل تنظيمية مزدوجة لتطبيق وتنفيذ الإبداعات الحالية وتقديم إبداعات جديدة. كيفية التعامل مع الطوارئ المتعدة التي تواجه الجامعة. التحول من البنى الآلية ذات الارجة العالية من المركزية والتسلسل الهرمي والتوحيد إلي الهياكل العضوية ذات المستويات العالية من اللامركزية والاستقلال الذاتي. 
قدرة الجامعة إلي أن تكون أكثر اتساقًا وفعالية، والتركيز علي سلطة صنع القرار. • التحول من النماذج التقليدية إلي النماذج الجديدة والمبتكرة. •بناء المعرفة والقدرات الجديدة لتحقيق ميزة تنافسية عالية. • القدرة علي التوفيق بين البراعة الداخلية للجامعة والتي تتمثل في الهيكل التنظيمي ككل والبراعة الخارجية لها. •تشيع الأفراد علي كيفية تقسيم وقتهم بشكل أفضل في إداراتهم لمطالب الأعمال.

$$
\text { تقديم التحفيز والتوجيه لجميع العاملين في الجامعة. }
$$

مما عرض سابقاً يمكن القول بأن أهداف الجامعة كمنظمة بارعة بحيث يمكن تلخيصها في قدرة الجامعة علي متابعة أعمالها الحالية لكي تتكيف مع البيئة الخارجية، توزيع مهامها واهتماماتها ومواردها بين هذين التوجهين الاستكثاف والاستغلال بالشكل الذي يضمن لها النجاح والاستمرار، تحسين أعمالها مع وجود المرونة فيها، الانتقال من النماذج البسيطة إلي النماذج المعقدة.

\section{r. ائص المنظمة البارعة بالجامعات:}

تمتلك الجامعة كمنظمة بارعة عدة خصائص تتبع من داخلها وتميزها عن غيرها من الجامعات مما يؤدي إلي تفوقها في الحاضر والمستقبل وتحقق التقوق والأفضلية علي المدي الطويل ومن أهم الخصائص التي تتمتع بها الجامعة كمنظمة البارعة ما

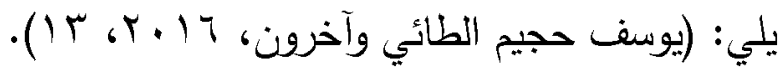

$$
\begin{aligned}
& \text { أ- استخدام استراتيجيات التوافق. }
\end{aligned}
$$

ب- استخدام الأعمال الحالية لاكتشاف فرص جديدة. ج- الاستثمار الأمثل في المشروعات المستقبلية.

د- إدارة الأعمال المتكاملة أو الرائجة أو الناضجة فضلاً عن الأعمال الجديدة. 


\section{هـ - تشجيع الأعمال الناشئة.}

و - استجابة للمتغيرات البيئية عن طريق تعديل هيكلها الداخلي والحفاظ علي علاقة تماثلية مع البيئة، وأن الهياكل الميكانيكية هي الأكثر مناسبة للظروف البيئية المستقرة نوعا ما، والهياكل العضوية تكون أكثر ملائمة للظروف البيئية

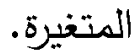

ز - إنشاد النجاح في عملها عليها استثمار الحاضر لأجل استشراف المستقبل، وهذا يقود إلي تحسين استراتيجية المنظمة لإيجاد أعمال متطورة وتحسين الثقافة التنظيمية.

يتضح مما سبق بأن المنظمة البارعة تتميز بمجموعة من الخصائص منها القدرة علي التكيف والمرونة في أداء أعمالها، تثجيع الأفراد علي القيام بأعمالهم علي أكمل وجه، تحقيق التوازن بين أنثطة الاستكثاف وأنثطة الاستغلال، ووضع مجموعة من الأهداف وترجمة هذه الأهداف إلي مجموعة من الإجراءات التي يتم تنفيذها علي أرض الواقع، القيام بالأعمال الحالية مع إيجاد الفرصة لاستكشاف أعمال جديدة تحسن من أداء المنظمة. وتظهر الجامعة كمنظمة بارعة في عدة خصائص منها: صياغة أهداف واضحة ووضع مجموعة من القرارات التي تدعم ذلك، تكوين فرق عمل كبيرة لصياغة استراتيجية واضحة ومتميزة وبارعة، ابتكار عمليات وهياكل جديدة تستجيب للتعامل مع المتغيرات البيئية، قدرتها علي استغلال الحاضدر من أجل استشراف المستقبل، وأيضا القدرة علي الاستكثاف والاستثمار وإدارة المشاريع المستقبلية، تطلعها للسعي للريادة في الابتكار وذلك لأجل إضافة قيم جديدة للمنظمة، قدر الأفراد علي التكيف والتوافق والتفاعل مع الجامعة. ع. أبعاد المنظمة البارعة بالجاهمات: 
(O'Reilly \& Tushman, 2013, يمكن تحديد أهم أبعاد المنظمة البارعة كما ذكره

إذ ترتكز الجامعة كمنظمة بارعة علي أربعة أبعاد رئيسية وهي كالآتي:

Simultaneous or Structural •

\section{Ambidexterity}

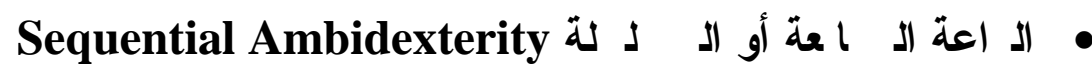

Contextual Ambidexterity a

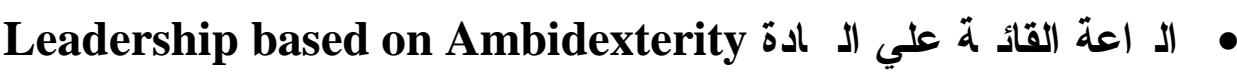
ا- الـ اعة اله لـ أو الآذة

\section{Ambidexterity}

من الطرق المهمة التي تتبعها الجامعات اليوم في عملية تحقيق التوازن بين استكثاف الفرص والعمل علي استغلالها، من خلال السعي إلي اتباع منهج متكامل والتزكيز علي الكفاءات والأنظمة والحوافز والعمليات، والبرامج الخاصة بالثقافة الداخلية للجامعة وأن يكون لاي الجامعة خطط استراتيجية مثتركة علي مستوي الهيكل التظيمي ككل، والعمل علي مجموعة شاملة من القيم تستهاف التركيز علي مفتاح البراعة والذي يتمثل في قدرة الجامعة علي العمل علي اغتنام الفرص الجديدة من خلال الاستكشاف والاستغلال في وقت واحد.

وهي التي تتضمن فصل الاستكشاف عن الاستغلال في الجامعة لتغطية المطالب المتناقضة، وهن خلا هيكل مزدوج في الجامعة، الآليات المتكاملة الرسمية وغير الرسمية يجب أن تستخدم لتضمن تدفق المعرفة عبر الوحدات الاستكثافية والاستغلالية وق يكون الانفصال ضروريا بسبب الطبيعة المختلفة للأنشطة الاستكثافية والاستغلالية

.(Kraner,2018, 27)((Gschwantner \&Martin,2016,374-375) 
وتظهر البراعة الهيكلية في قدر الجامعة علي التوفيق بين إداراتها للمطالب

المتضاربة مثل المحاذاة والقدر علي التكيف عن طريق وضعها موضع التنفيذ " الهياكل المزدوجة " بحيث يكون هناك وحدات عمل معينة أو مجموعات داخل وحدات العمل بحيث يتم التركيز علي المحاذاه وفي الجانب الأخر التركيز علي التكيف بحيث تشير المحاذاة إلي التوافق بين جميع أنماط الأنشطة في وحدة العمل بحيث يتم العمل معا لتحقيق نفس الأهداف، بينما القدرة علي التكيف تثير إلي القدرة علي إعادة تكوين الأنشطة في وحدة الأعمال بسرعة لتلبية المتطلبات المتغيرة وهذه القرات معقدة وتحتاج إلي وقت طويل لتنفيذها ويمكن تحقيقها داخل الجامعة من خلال إنشاء هياكل مزدوجة، وبناء مجموعة من العمليات والأنظمة التي تشجع الأفراد علي إصدار أحكامهم الخاصة حول كيفية تقسيم وقتهم بين المطالب المتعارضة لأنشطة المحاذاة والتي تكون موجهة نحو تحسين الأداء علي المدي القصير وأنشطة القدرة علي التكيف والتي تكون موجهة نحو تحسين الأداء علي المدي الطويل، وتكون من أعلي لأسفل (Chang,et وتتحقق أيضا من خلا الفصل الهيكلي وتقسيم المهام والقيادة المناسبة )

$$
\text { .al., 2016, 8) }
$$

وأثشار (2004,50-51, Birkinshaw \& Gibson) أن البراعة الهيكلية هي إنشاء هيكل منفصل لأنواع مختلفة من الأنشطة، وتتحقق البراعة الهيكلية في الجامعة

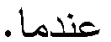
يتم تركيز الأنشطة التي تركز علي المحاذاة والقدرة علي التكيف مع وحدات منفصلة للفرق.

توضع القرارات الأولية والتي تقع بين المحاذاة والتكيف في قمة المنظمة. للإدارة العليا دور في تحديد الهيكل، لجعل المبادلات التجارية بين المحاذاة والتكيف. 
طبيعة الدور الذي تقوم به واضـح نسبيا وهحد.

مهارات الموظفين تكون أكثر تخصصا.

\section{r- البراعة المتتابعة أو الـ لـ لة Sequential Ambidexterity}

هناك رأي يقول أنه من الممكن أن الجامعات تعيد تنظيم هيكلها بسبب الظروف ري البيئية المتغيرة وعلي ضوه هذا التغيير يمكن أن تطور استراتيجياتها وهذا يجعلها متكيفة مع البيئة لخلق حالة من الاستكثاف واستغلال الفرص البيئية وتطور الجامعات في عملية التكيف لهياكلها ولاسيما مع متغيرات السوق وكيفية مواجهة التغير والعمل علي تكيف هياكلها والعمليات الخاصة بها. وهنا لابد أن تصاغ نظرية التوانن بين الجامعات والتغيرات البيئية وضرورة التوازن ما بين هياكلها وإعادة تصميمها وعملياتها والبيئة عبر عمليات متسلسلة وهذا مرتبط بالزمن وكلما كانت الجامعة كمنظمة بارعة قادرة علي التكيف مع الزمن والتغير الحاصل في البيئة استطاعت تحقيق الميزة التنافية المناسبة لها. ويمكن أن يكون هذا واضتح في الجامعات الإكترونية الصنيرة وكيف يمكن لهذه الجامعات أن تتكيف مع المتغيرات التكنولوجية، والمتغيرات التي تطرأ علي المنتجات، وهنا وضح الباحثو ن وبعد جدل طويل حول هذا الموضوع العديد من النقاط الرئيسية حول هذا الموضوع وهي. أ- إمكانية الجامعات استبدال هياكلها الرسمية بالهياكل غير الرسمية. ب-التغير في الثقافة التنظيمية وبما يتلاعم مع البيئة الخارجية. ج- يمكن أن تكون المتغيرات المتسلسلة في الهيكل التظيمي عن طريق تعزيز اللامركزية المؤقتة في عملها نتيجة التغيرات البيئية. وهذه العملية تساهم في اكتثاف واستثمار الفرص البيئية التي يمكن أن تستغلها الجامعة مما يجعلها بارعة في نظام عملها، وهذا يركز علي البراعة المتتابعة والتي 
تحدث علي مدي فترات طويلة من الزمن، وهذه البراعة تعد من الآثار الإيجابية علي نمو الجامعات وتطورها.

وتتحقق البراعة المتسلسلة في الجامعة عن طريث إعادة تنظيم هياكلها للتكيف مع ظروف البيئة المتغيرة، ويمكن استخدام هياكل نصفية للتوانن بين فترات الاستكشاف والاستغلال وتسمي هذه العملية بالتنبذب حيث تستطيع الجامعة التبديل بسهولة بين الهياكل الرسمية والهياكل غير الرسمية، والتسلسل يساعد علي التغيير في الهيكل التنظيمي لتعزيز اللامركزية بحيث يمكن أن تكون فعالة لأنشطة الاستكثاف والاستغلال، وتتحقق أيضا عند استخدام وسائط متزامنة لكل من الاستكثاف والاستغلال.

\section{Contextual Ambidexterity}

البراعة السياقية هي القدرة السلوكية لإثبات التوافق في وقت واحد، أو القدرة علي التكيف عبر وحدة الأعمال بأكملها، لتحقيق التوانن بين الاستكثاف والاستغلال من خلال سياق تنظيمي يتسم بمزيد من التفاعل والتقة والانضباط، يتطلب ذلك تشجيع الأفراد علي إصدار أحكامهم الخاصة بكيفية تقسيم وقتهم بشكل أفضل من خلال المحاذاة والقدرة علي التكيف في إداراتها لمطالب الأعمال، وهي مجموعة من العمليات والأنظمة داخل الجامعة التي تسهل وتشجع الوحدات التتظيمية للقيام بمهام متتاقضة في نفس الوقت، وفيها لا توجد أي تعليمات أو أوامر واضحة من الجامعة للعاملين نحو الإجراءات الأستكثافية والاستخلالية وعلي ذلك يأخذ كل فرد هذه الإجراءات بناء

علي حكمه (Birkinshaw\& Gibson,2004). حيث يعتمد عمل العاملين فيها علي الاحتياجات الحالية، وهي تعني التكامل والسعي المتزامن للأنشطة الاستكثافية والاستغلالية في عمل وحدة واحدة، وهذا النهج يتطلب أنظمة أكثر مرونة، والهياكل التي تسمح للعاملين أن يقرروا من تلقاء أنفهح كم 
من الوقت يريدون الاستثمار في الأثنطة الاستكثافية أو الأنثطة الاستغلالية .(Enger, et al., 2015)(Raisch\& (Birkinshaw,2008,11-12) وتختلف البراعة السياقية عن البراعة الهيكلية فيما يلي.

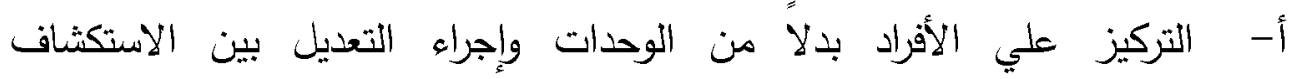

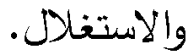
ب- يتم تحقيق البراعة السياقية عندما يتفق الأفراد علي أن وحدتهم محاذاة وقابلة للتكيف. ج-النظم والعمليات التنظيمية التي تمكن هذا التعديل الفردي لم يتم تحديدها بشكل ملموس بخلاف أنها تعزز الامتداد والانضباط والثقة مثل تأدية الأفراد في المنظمة لمهامهم اليومية الروتينية وهذا يسمي (استغلال)، ولكن عندما يغيروا وظائنه باستمرار ليصبحوا أكثر فاعلية (استكشاف) هذا يسمي بالروتينيات الفوقية أو ما يشار إليه بالتوافق التوافقي. وتوجد طريقة بديلة لوضع تصور البراعة السياقية وهي القدرة علي المواءمة والتكيف بوصفها تقافة الجامعة التي تشجع كلاً من المرونة والتحكم داخل الوحدة الواحدة في العمل، وأن قواعد التكيف تتمثل علي سبيل المثال المخاطرة، وسرعة اكتثاف القرص، الابتكار ، وترتبط مع الأداء القوي في البيئات الديناميكية. وتتحقق البراعة السياقية في الجامعة عندما-Birkinshaw \& Gibson, 2004, 50)

يقسم وقت العاملين بين الأنشطة التي تركز علي المحاذاة والأنشطة التي

$$
\text { تركز علي القدرة علي التكيف. }
$$

توضع القرارات التي تنقسم بين المحاذاة والتكيف علي الخط الأمامي من قبل موظفي المبيعات- موظفي المكاتب- مكتب المشرقين. 
لملإدارة العليا دور في تطوير سياق الجامعة في أي فعل فردي.

طبيعة الدور الذي تقوم به مرن نسبيا.

$$
\text { مهارات العاملين أكثر عمومية. }
$$

وفي نفس السياق تتحقق البراعة السياقية في الجامعة عندما يسير القادة في وحدة الأعمال علي سياق تنظيمي داعم، ولا يتحقق أداء وحدة الأعمال من خلال القيادة الكاريزمية ولا من خلا الهيكل التنظيمي الرسمي أو ثقافة قوية، ولكن يتحقق ذلك ببناء مجموعة من النظم والعمليات التي تكون مجتمعة السياق الذي يسمح للقدرات بالمحاذاة والقدرة علي التكيف في وقت واحد وبالتالي الحفاظ علي أداء وحدة الأعمال، ولا تتحقق البراعة الهيكلية عن طريق الانفصال الزمني إنما عن طريق بناء سياق الأعمال التي تثجع العاملين علي القيام بأحكامهم الخاصة لتقسيم الوقت بين المطالب المتضاربة المحاذاة والقدرة علي التكيف التي تتخلل جميع الوظائف والمستويات بذلاً من الهياكل المزدوجة وهذا يكون نموذج أكثر استخامة وهذا أفضل من الفصل الهيكلي لأنه يسهل تكيف وحدة العمل بأكملها، حيث يتم إعطاء العاملين تعليمات واضحة وتلقي الحوافز التي تدعم أنشطة إما المحاذاة أو التكيف ولكن في وحدة بارعة السياق للكيفية التي تسمح للعاملين بتقسيم وقتهم بين الأنشطة والتوفيق بين المرونة والكفاءs (Birkinshaw \& Gibson,2004,209) . وتشمل البراعة السياقية أربع سمات وهي الامتداد- الانضباط- الدعم- الثقة وتنقسم إلب بعدين.

البعد الأول: إدارة الأداء وهي تجمع بين (الامتداد والانضباط) حيث تهتم بتحفيز العاملين لتقديم نتائج عالية الجودة وجعلها مسئولة عن أفعالهم، ويشير الامتداد إلي السياق الأي يكون فيه العاملين علي استعداد لتحقيق أهداف أكثر طموحا، والانضباط هو السمة التي تشجع العاملين علي تحقيقها وما يفترض القيام به. 
البعد الثاني: الاعم الاجتماعي وهي تجمع بين (الدعم والثقة) حيث تهتم بإشعار العاملين بالأمان وتتمية أدائهم، وإدارة الأداء والاعم الاجتماعي متبادلين التساوي في الأهمية، والحضور الأقوى سوف ينشئ أداء عال لسياق الجامعة بحيث يؤدي حقًا إلي جامعة كمنظمة بارعة، حيث يشير الاعم إلي أنه يتضمن سياقا يشجع العاملين علي المساعدة وتحمل بعضهم بعضا، في حين تمثل الثقة السمة التي تخلق بيئة عمل موثوقة حيث مزيج من الأداء السياقي يؤدي إلي مستوي أعلي من الأداء التنظيمي.

داع الـ اعة القائ ة علي الـ ادة Leadership based on Ambidexterity تصبح الجامعة بارعة من خلال القيادة حيث القادة يقودوا الجامعة من خلال عمليات الاستكشاف والاستغلال، ولكي تصبح الجامعة بارعة فإنها تحتاج للتعامل مع الإدارة المتناقضة والأهداف المتعارضة الاستكثاف مقابل الاستغلال ويكون في نفس الوقت مع نفس الجامعة للقدرة علي التعامل مع التقافات المختلفة. وتتحقق البراعة القائمة علي القيادة في الجامعة من خلال قدرة القادة علي الخروج من العمل الروتيني التتريس والبحث العمي وخدة المجتمع إلي استكثاف فرص جديدة في التدريس والبحث العلمي وخدمة المجتمع، وتوزيع المهام والموارد والوقت بين أنشطة الاستكشاف وأنشطة الاستغلال بشكل متزامن للتغلب علي التوترات المتناقضة للتعلم وتحقيق النجاح في العمل، وتحقيق التوازن بين السلوكيات المنفتحة التي تحفز التفكير عند اختلاف سلوكيات العاملين كالسماح بالأخطاء، وبين السلوكيات المنغلة التي تتضمن اتخاذ الإجراءات الصحيحة ووضع الخطوط الإرشادية (Zacher \& Rosing,2015,65)، والجامعة كمنظمة بارعة تستطيع أن تتفوق من خلال التركيز علي إما الاستكثاف أو الاستغلال. ثانياً: واقع تهقيق المنظمة البارعة بالجامعات المصرية: 
يتناول هذا الجزء من البحث واقع الجامعات المصرية من حيث الوضع الحالي لأدائها،

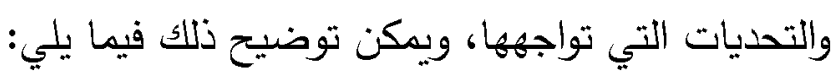

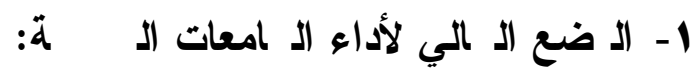

تواجه الجامعات المصرية مشكلات تربوية عديدة تعيق حركتها، وهذه المشكلات

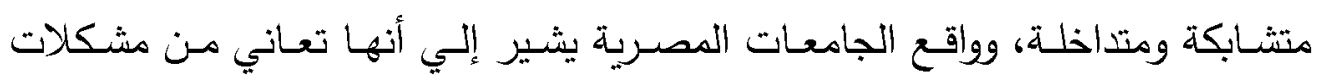

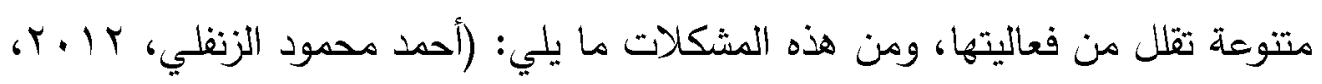

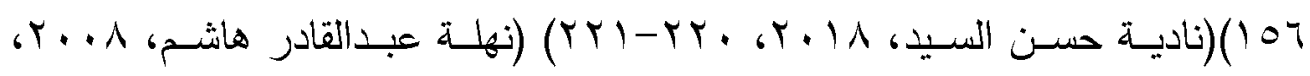
$\cdot(r \leq \varepsilon$

- الميل إلي النمطية في النظم واللوائح والمناهج، واتساع الصـلاحيات في التنظيم الإداري، حيث تظلب المركزيـة علي العمل الإداري في التعليم الجامعي، وهرمية التهاتية التنظيم الإداري.

- - غلبة الجو البيروقراطي علي الجامعة ووحداتها المختلفة ، سواء علي مستوي إدارك

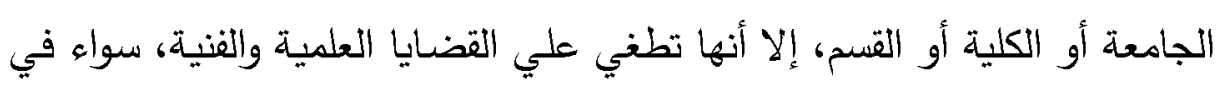

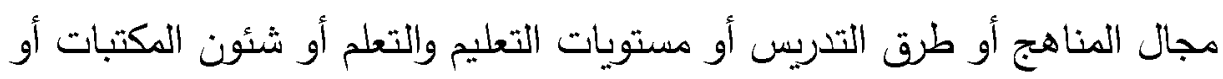
التعلم الذاتي أو قضايا البحث العلمي.

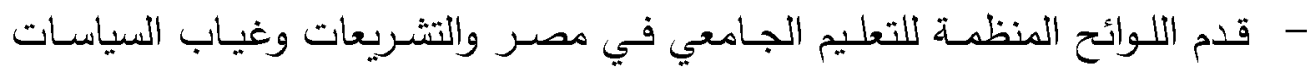

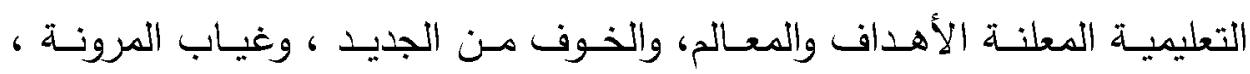
ومقاومة التغييز • 
- عزلة الجامعات عن التفاعل الإيجابي لتلبية احتياجات سوق العمل، حيث ينحصر دورها في إعداد الخريجين المؤهلين بالكفايات والمهارات اللازمة، وهذا نتيجة غياب الارتباط بين سياسات التعليم الجامعي والقوي العاملة وقطاعات المجتمع - التتمية المهنية لأعضـاء هيئة التدريس، حيث يواجه أعضاء هيئة التدريس العديد من المشكلات كالأمن الاقتصادي، فانخفاض مرتباتهم يؤدي إلي تسرب عدد كبير من الأساتذك ذوي الخبرة العالمية إلي البلدان ذات الاخل المرتفع.

- كما تواجه الإدارة الجامعيـة مشكلة سيادة ثقافة الأفراد داخل الجامعات، وغياب ثقافة النظام عند تغيير القيادات، سواء علي مستوي الإدارة العليا أو علي مستوي إدارة الكليات، أو الأقسام.

- - يغلب الجمود علي التعليم الجامعي الأي أرسي دعائمه قانون الجامعات، وهو ما انعكس بالسلب علي جوهر العملية التعليمية ومحتواها من ناحيتين: أولهـا: غياب التخصصـات المواكبة لروح العصـر ، وثثان هــا: محدوديـة مشـاركة أعضـاء هيئة التدريس في التـدرج الجـامعي، والمفترض فيه م أنهم المعنيون بالارجـة الأولبي بصياغة سياسات الجامعة ، فالجامعة تشتمل علي نظام للكليات أو نظام للأقسام التي يفصل بينها العديد من الحواجز ، وهو ما أدي إلي الافتقار إلي مرونة تسمح ببلورة نظام بيئة متداخلة التخصصات، أو متجاورة التخصصات في هذه المنظومة، ومن هنـا برز الاحتيـاج إلي صـيغ تتواكب مـع متغيرات العصـر، وتتماشـي مـع صعود أهمية المجالات البيئية والتخصصات المشتركة.

وهنالك من يري أن الجامعات المصرية تواجه مجموعة من المشكلات وتتطلب

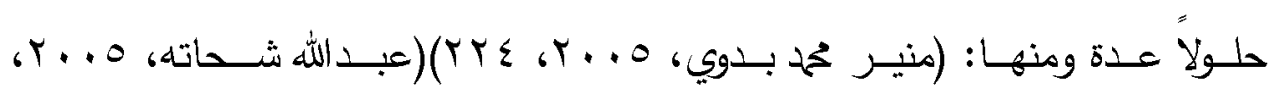




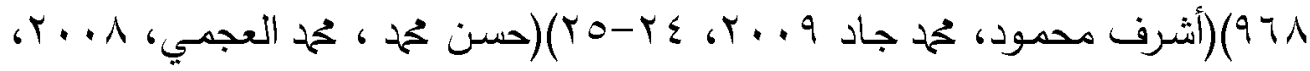
$(\wedge \cdot-\vee 9$

- إهمال معايير الكفاءة والتميز في اختيار القيادات حيث إن كفاءة التعليم رهن كفاءة الإدارة ورهن بكفاءة إدارتها وبقدرتها علي التجديد والتطوير في أساليب الإدارة، ومرور فترة طويلة من الزمن علي صدور القوانين التي تحكم الجامعات المصرية وعلي الرغم من تطوير بعضها إلا أن روحها بقيت علي حالها مقيدة للعمل وقاتلة لأية مبادرات أو جهود تطويرية . - غياب معايير تقييم الأداء للجامعات المصرية لضمان جودة مخرجاتها وتحقيق التميز، حتي يتم الكشف عن جوانب القصور بها أو تدعيم

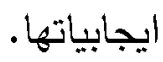

- - ضعف الثقافة التنظيمية لدي العاملين بالجامعات، والتي تعد المحرك الأساسي للطاقات والقدرات، ونقطة بداية الانطلاق للتطوير والتغيير الفعال

$$
\text { وعدم الأخذ بأساليب قيادية جديدة. }
$$

- تتجسد الأزمة الحقيقية للجامعة في أنها تمركز جهودها في أدائها حول الدور التعليمي، ولقد أدي التركيز علي هذا الدور إلي فكرة جامعة الحرم المغلق وهي جامعة تنغلق علي نفسها، ولا تسعي لقيادة المجتمع بقدر ما تسعي لتلبية ما يملي عليها من سلطة المجتمع، وقد يؤكد هذا الفهم المقارنة بين الأنشطة التي تقوم بها الجامعة داخل أسوارها، وتلك التي تقوم بها خارجها. - البطء في استجابة الجامعات لمطالب التطوير المستمر نظرا لتعقد الإجراءات البيروقراطية. 
- ضعف قدرة الجامعات المصرية علي الاستجابة السريعة والمتلاحقة

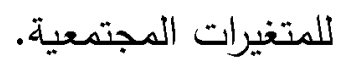

- انحصار بعض الجامعات المصرية في الحيز المحلي وعدم انطلاقها إلي التعامل مع المصادر العالمية سواء في استقطاب الطلاب أو أعضاء هيئة التدريس أو مصادر المعرفة والتمويل.

- - ضعف الإمكانات المادية للجامعات المصرية متمثلة في مبانيها ومعاملها وتجهيزاتها.

- - جمود الخطط الدراسية ومناهجها، وعدم ملاحقتها لمستحدثات العصر . - ضعف الأنظمة الفعالة للمتابعة والتقويم والتي يمكن من خلالها الحكم علي مدي كفاءة هذه المؤسسات لتحقيق الأهداف المنشودة.

- استدامة التمويل العام للخدمة التعليمية المقدمة للعدد المتزايد بالجامعات، لأن موازنات التعليم العالي لا تمثل الاحتياجات التصاعدية للكليات ، كما أنها لا ترتبط بتثييم مخرجاتها التعليمية.

- - مفف المخرجات وعدم قدرتها علي المنافسة في الأسواق العالمية، وفقدان مصداقية بعض الشهادات التي تمنحها الجامعات المصرية.

يستخلص مما سبق ان الجامعات المصرية تواجه الكثير من المشكلات، و بليها التخلب علي هذه المشكلات، لتحظي بتعليم يسعي إلي تحقيق التميز والوصول إلي البراعة في أدائها وتحسين خدماتها، وتكون قادرة علي المنافسة الدولية في ظل المتطلبات العالمية، ومن ثم أصبح تحويلها لجامعة بارعة مطلبا أساسيا لرفع كفاءة 
مخرجات العملية التعليمية والارتقاء بمستويات الخريجين ورفع كفاءتهم، وتصبح الشهادات التي يحصلون عليها معترف بها عالميا.

ويقع علي التعليم الجامعي عبه إعداد وبناء جيل جديد يحمل أفكار وثقافة

متميزة لكي يواجه تحديات العصر ، ويجي تطبيق المعرفة بثكل من لملاحقة المتغيرات المعاصرة، وذلك من خلا تطوير محتوي برامج التعليم الجامعي علي أسس سليمة ومتوافقة مع المستحدثات الاخاخلية والخارجية.

ويشير واقع الجامعات المصرية أنه علي الرغم من التطورات التي حدثت لتطوير وجودة مخرجاتها، إلا أنها ما زالت تحتاج إلي الجودة لتصبح أكثر تطورا، وفي هذا الأمر أشارت الأديبات التربوية والدراسات السابقة إلي وجود الكثير من التحديات ا لتي تؤدي إلي تلني محتوي برامج التعليم الجامعي وضعف استجابته، بالإضافة إلي ضعف تحقيق الجودة والتميز في البرامج التعليمية والبحثية، كما تقف الجامعات المصرية أمامها العديد من المشكلات التي تحول دون تحقيق التميز في أدائها، عدم ملائمة استراتيجية الجامعات مع التوجهات العالمية وعدم وجود سياسة واضحة للتعامل

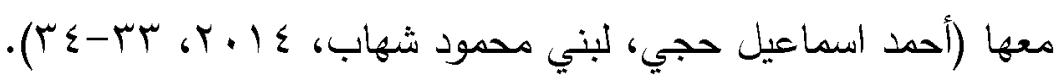

مما سبق يمكن القول بأن الجامعات المصرية تواجه مجموعة من التحديات التي تحول دون تحقيق أهدافها والتي تتمثل فيما يلي: - - ضعف قدرة الجامعة علي القيام بمهمة تتمية التفكير العلمي لاي الخريجين، وعلي التفكير بأسلوب علمي في المواقف الحياتية المختلفة.

- ضعف قدرة الجامعة علي مواجهة التحديات المحلية والعالمية وصياغة ملامح المستثبل المنشود. 
- ضعف استغلال الجامعة للموارد والإمكانات المتاحة بما في ذلك الموارد

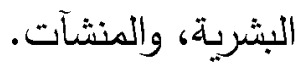

- - - القصور في التتسيق بين التعليم الجامعي ومتطلبات سوق العمل. - - تعدد اللوائح والقوانين، وتعدد مستويات الرقابة. - - تلني كفاءة خريجي التعليم الجامعي، والقصور في الإعداد الأكاديمي

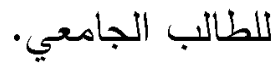

- ضعف وجود رؤية ورسالة واضحة بمتطلبات سوق العمل بالجامعات المصرية.

- - التكنولوجي.

- - الاعتماد علي الوسائل التعليمية التقليدية وقلة الاهتمام بالتكنولوجيا الحديثة. - - تمركز السلطة في المستويات الإدارية العليا بالجامعات المصرية. - -

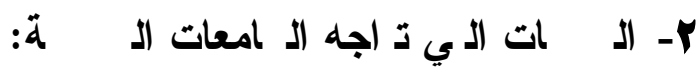
هنـاك العديــــن التحولات والمستجدات العالميـة التي تواجـه التعليم الجـامعي وتتطلب إعادة هيكلة التعليم الجامعي وهذه التحديات تعيشها الجامعة وتتفاعل معها، وتحيط بالجامعة أيضـا ، ممـا يجعل الجامعـة مجبرة علي الإحاطة المتعقةـة بها، 
واستيعابها والتفاعل معها وهذه التحديات كما يلي: (أحمد اسماعيل حجي، لبني محمود

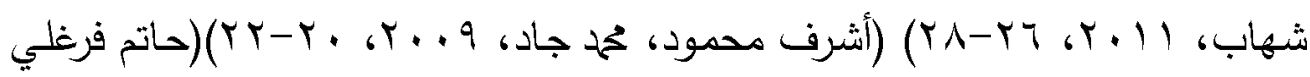

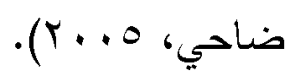

- فرضت التحديات العلمية والتكنولوجية ظهور التعليم الجامعي الإكتروني، وتزايد استخدام الإتترنتـ، وظهـور المكتبـة الرقميـة، وتطـور المنـاهج، وتطور مجـالات البحث العلمي، والتوجه نحو تكامل المعرفة والاهتمام بالتخصصات البيئية والتكيف كر كر مع متطلبات مجتمع المعرفة، وظهور نظم جديدة للتعليم الجامعي عن بعد، وهذا فرض علي الجامعة تبني نماذج حديثة مثل الجامعة الإكترونية، الجامعة الذكية، مراكز البحث العلمي وتطوير مراكز التميز.

- فرضت التحديات السياسية ظهور ديمقراطية التعليم الجامعي ، والتوسع في الفرص التعليميـة، ودعم الاستقلال الجـامعي، والاهتمـام بتعليم الكبار وهذا فرض أدوارا جديدة علي التعليم الجامعي ، نشر ثقافة السلام ونبذ العنف، والأخذ بصيغ جديدة لتحقيق تكافؤ الفرص التعليمية مثل: مشاركة الجامعة في تعليم الكبار والجامعات

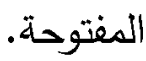

- فرضت تحديات العولمة تزايد الاهتمام بالتربية الدولية، وتطبيق مدخل إدارة الجودة الثاملة التي تؤدي إلي تحقيق التميز التنظيمي بالجامعات، زيادة التعاون والتبادل العمي بين الجامعات ومراكز البحوث، تحالف الجامعات عبر الأنترنت، وتحقيق ميزة تنافسية وتحويل الجامعة كمنظمة بارعة. - فرضـ التحديات الاقتصـادية خصخصـة التعليم الجامعي، وتزايد اهتمام الشركات متعددة الجنسيات بالتعليم الجامعي، وتطبيق المعايير الاقتصـادية علي الأنظمـة 
التعليمية وتوثيق العلاقة بين التعليم الجامعي وقطاعات العمل والإنتاج والبحث عن مصادر تمويل إضافية، ولذلك ظهرت مجموعة من الأدوار لمواجهة هذه التحديات تمثلت في: تحقيق التنمية الاقتصادية، تبني نماذج جامعية حديثة مثل الجامعات الذكية، الجامعات الافتراضية، الشراكة بين الجامعة والمؤسسات الإنتاجية والخدمية وتسويق المنتجات الجامعية، ظهور نماذج جامعية حديثة مثل الجامعة المتمركزة حول السوق وصيغ الجامعة من أجل الصناعة.

- فرضت التحديات الإعلامية والثقافية تزايد التقارب بين الجامعات ووسائل الإعلام، وزيادة الاهتمام بوسائل الإعلام التربوي والتقارب التقافي والسلام العالمي، وظهور جامعـة الهواء والاهتمـام بـالتعليم متعدد الأغراض، وقد فرض عدة أدوار منها: الحفاظ علي الهوية التقافية والنهوض باللغة العربية. - - وفرضت التحديات البيئية تزايد الاهتمام بالتربية البيئية والتنمية المستدامة، وظهور التعليم من أجل التمية للمعايش، وقد فرضت هذه التحديات أدوارا جامعية جديدة مثل: نشر الثقافة البيئية والمجتمعية والمساهمة في إنتاج تكنولوجيا نظيفة، وتحقيق التنمية البشرية المستدامة وتبني نموذج جامعة البيئة.

- - تعليم القرن الحادي والعشرين إذا كان التعليم العربي يفتقر إلي الكفاءة، فإن التعليم للقرن الحادي والعشرين وخاصة التعليم الجامعي ينبغي أن يكون تعليما متميزا يتاح للجميع دون تمييز وهذا القرن شهد تغييرات جذرية وأننا في الطريق إلي أن تصبح المهن جميعا مع اختلافها أكثر تعقيدا نتيجة صبغها بلا استثناء بالتكنولوجيا، يسعي الأفراد إلي خلق فرص عمل لأنفسهم بجانب فرص العمل التي يشتغلونها ليوفروا لأسرهم حاجاتهم المتزايدة وتحقيق المتزايدة، وتحقيق الرفاهية، وهذه الأعمال 
قد لا تكون في أماكن عمل تقليدية، تتزايد حاجات الأفراد لأن يكونوا علي دراية بالثقافات الأخرى وحضارات الغير وتعلم اللغات الأجنبية واستخدامها بإتقان، تزايد صعوبات الحياة في مجالات متنوعة، ولذلك فإن تعليم القرن الحادي والعشرين ينبني أن يلبي احتياجات المتعمين والمجتمع يواجه التحديات، تعليم يبني علي وينهل من ويقدم- العلم والتكنولوجيا، والكمبيوتر ، واللغات، والقيم، ومهارات الحياء وتحسينها مثل مهارات التعلم الذاتي والمستقل والمستمر ، مهارات الحياة والعمل. - الجودة وتقويمها وهي أمر مرتبط بجميع الوظائف والأنشطة المتنوعة للجامعات، إنها تشمل التعليم والتدربب والبحوث العلميـة، وهذا يعني أن نوعيـة العاملين من أعضـاء هيئة التدريس وإدارينين وبرامج تعليم والبحث ينبغي أن تتصف بالجودة ويتضمن مفهوم الجودة الاهتمام بالمدخلات من طلاب وبني وبيئة أكاديمية، كما يتضمن الاهتمام بالعمليات التعليمية والبحثية والمخرجات وقياس أدائها. - الرقمنـه: وهي تطبيقت تقنيـات التحول الرقمي، والانتقـال بالخدمات التي تقدمها الجامعة إلى نموذج عمل مبتكر يعتمد على التقنيات الرقمية، يوفر التحول الرقمي كثيرا من الجها والمال، وتحسين كفاءة العمل، وتحسين الجودة وتبسيط الإجراءات، ويقدم فرصة للتوسع والانتشار بشكل كبير بين العاملين في الجامعة، عن طريق حلول مبتكرة وبسيطة بعيدا عن الروتين. ويتفق مـع مـا سـبق مـا حدده إدواردز (Edwards,2000,41) مجموعـة مـن التحديات والمطالب التي تواجه الجامعات المصرية منها: تزايد أعداد الطلاب الملتحقة

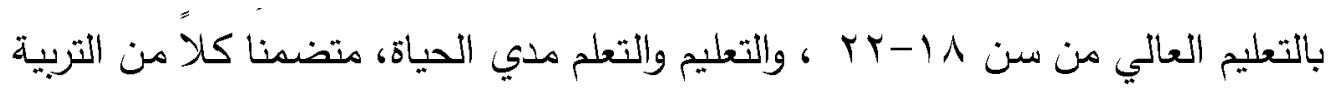
المستمرة للخريجين (وخاصـة التنميـة المهنيـة المستمرة) وتجهيز فرصـة ثانيـة للبالغين 
الذين لا يستطيعون دخول التعليم الجامعي مـع السن المتفق مـع القواعد المقرة، وكذلك

البحوث التطبيقية والتي لم تعد فقط تركز علي التكنولوجيا وعصر المعلومات، ولكن تركز أيضا علي المثكلات الاجتماعية الناتجة عن التكنولوجيا الجديدة وعولمة السوق، والمساهمة الاقتصادية، وتحسين الحياة الاجتماعية للمجتمع، كما شملت أجندة التعليم العـالي مجموعـة مـن الأمسور يجب أن تؤخذ في الاعتبـار منهـا: توسـيع المشـاركة، التحديث، والجامعات الاككترونية، والأعمال والمجتمع، والتنوع، والمحاسبية.

وبناء علي ما سبق، فإن الجامعات تواجه العديد من التحديات المحلية والقومية والإقليمية والعالمية في عالم سريع التغير في المعرفـة التي تمثل القوة في الاقتصـاد والمجتمع والمستقبل، وهذا يستـاعي مـن الجامعـات البحث عـن إدراك القوة الكامنـة لمستقبل مبني علي المعرفة، وهذا أدعي للكليات والجامعات لتقديم برامج أكاديميـة متميزة تحقق التميز المستمر علي المدي الطويل.

\section{ثالثاً: متطابات ثمقيق المنظمة البارعة بالمامعات المصرية:}

اعتمدت الباحثة في اشتقاق المتطلبات الأساسية اللزمة لتحقيق المنظمة البارعة بشكل فعال علي العرض السابق للإطار النظري للمنظمة البارعة، والدراسة النظرية لواقع الجامعات المصرية، وبعض الدراسات والأديبات السابقة، ويمكن تصنيفها إلي منطلبات تنظيمية وإدارية، ومنطلبات تشريعية، وذلك من خلال ما يلي: (Reynolds, 2014)

$$
\text { أولاً: مد دات ت }
$$

تتحدد أهم المتطلبات التنظيمية والإدارية اللازمـة لتحقيق المنظمة البارعة بشكل فعال 
ا- وجود آليات وقواعد معينة تسمح بالتطوير ومتابعة كل الأنظمة والعمليات التي تحقق الأداء المتوازن والتخطيط له بالشكل المطلوب.

r- التوعيـة الثـاملة والرؤيـة للعـاملين للتعامل مـع المعطيات والأسـس الجديدة لأجل أن أن ينطلق التغيير بسلامة نحو تحقيق الجامعة كمنظمة بارعة. r- تحديد الرؤيسة المستقبلية لما ينبخي أن تكون عليه الجامعات البارعة، ومشـاركة أفراد المجتمع الجـامعي في وضـعها، وتكوين الرغبـة الأكيدة لديهم لتحقيقها، بالإضـافة إلي لي وضع الاستراتيجيات اللازمة لتحقيقها.

ع- توفير الدعم من القيادات العليا بالجامعات لثقافة المنظمـة البارعة، وذلك من خـلال تطوير أداء أفراد المجتمع الجامعي، ودفعهم إلي تحقيق النجاح والتميز • ه- تتمية الكوادر البشرية بالجامعة من خلال تشجيع أعضاء المجتمع الجامعي من أعضـاء هيئة التدريس ومعاونيهج علي المناقشات البناهة، وتقديم الأفكار البارعة والمبدعة، وتنمية مهاراتهم ومعارفهم، والاعتراف بجهودهم الهادفة إلي تحقيق البراعة في العمل. ج- توفير الإمكانات المادية والتكنولوجية والمالية النلزمـة لضمان تحقيق المنظمة البارعة بالجامعات؛ وذلك من خلا إيجاد مصادر تمويل بديلة بجانب التمويل الحكومي، مثل: شراكة مؤسسات المجتمع المختلفة مـع الجامعات، تعظيم الاستفادة من الموارد المتوفرة بالجامعة لخدمة أهدافها. V- تمية ثقافة تنظيمية جديدة تشجع علي ترسيخ قيم ثقافة المنظمة البارعة وذلك من خلال عقد الندوات، ووش العمل، والاجتماعات مـع أفراد المجتمع الجامعي لتحويل تلك القيم والمعتقدات السلوكية المرتبطة بالمنظمة البارعة إلي واقع وممارسات عملية. ^- تبني الجامعات نماذج المنظمة البارعة التي تجعلها في مركز أفضل بالنسبة لغيرها من الجامعات الأخرى، وتحقق من خلالها نتائج غير مسبوقة بين مثيلاتها من الجامعات الأخرى. 
و- مراعاة التتوع في الاستعانة بالأساليب أو الأدوات المستخدمة لقياس نجاح الجامعات في تحقيق المنظمة البارعة؛ حيث إن كل أسلوب من الأساليب لـه خطواته المنهجية المحددة بما يساعدها علي تحقيق ميزتها التنافسية. • 1- إحداث تطوير في النظم الإدارية المنظمة للعمل الجامعي، من خلال تجنب التعقيدات الإدارية والمعوقات البيروقراطية في العمل، وتخفيض عدد اللوائح والقوانين المكبلة للعمل البارع. 11- استحداث وحدات للأنشطة الاستكثافية والاستغلالية التي يمكن أن تساعد في تقديم بعض الخدمات المتتوعة التي تلبي احتياجات المجتمع الجامعي والمجتمع الخارجي بما يجعلها جامعة بارعة ورائدة في تقديم خدماتها. rا- القيادة والالتزام: توفر مجموعة من القادة القادرين علي استغلال الفرص التنظيمية وتوفير الفرص التطويرية التي تشجع علي الإبداع والابتعاد عن الروتين

$$
\text { والبيروقراطية. }
$$

rا - وضع رؤية استراتيجية وخطة عمل يقوم بها مجموعة من المتخصصين ولايهم قدرة علي التطوير ولايهج رؤية مستقبلية قادرة علي تحقيق التوانن بين أنثطة الاستكثاف وانثطة الاستغلال لتحقق في النهاية الجامعة البارعة.

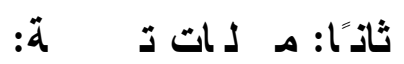

وتتحدد أهم المتطلبات التشريعية التي تسههم في تحقيق المنظمـة البارعـة بالجامعـات

$$
\text { المصرية فيما يلي: }
$$

1-وضع التشربعات والأنظمة المناسبة التي تسمح بلخول وتحقيق أي تغيير يمكن أن يحدث في الجامعات ويتمتع بقدر من المرونة المناسبة التي تساعد علي التطوير بحيث تتمشي مع متطلبات المنظمة البارعة. 
r- إنشاء بنية تنظيمية مناسبة تشمل الأنماط والعمليات والثقافات التي تحافظ علي الوضع الراهن مع السعي لتحويلها إلي منظمة بارعة.

r- وجود هيكل تتظيمي مرن يسمح بتخصيص المسئوليات والوظائف والعمليات المختلفة وتكون فعالة ومرنة ومبتكرة من أجل تحقيق ميزة تنافسية مستدامة. ع-تدعيم القدرة المؤسسية للجامعات المصرية، من خلا تعظيم الاستفادة من نظم المعلومات ومصادرها، والمعامل، والبنية التحتية المتاحة ودعمها، واستخدام التقنيات الحديثة في التعليم والتعلم، واستيعاب التخصصات العلمية الحديثة والمجالات الإبداعية والابتكارية، وتقوية الروابط بين الجامعات والمجتمع والصناعة وسوق العمل لإحداث التطوير المستمر . ه- السعي نحو تنمية كفايات أعضاء المجتمع الجامعي لكي تستوعب عمليات التطوير والتحسين المستمرة. 7- إصدار القوانين والقرارات واللوائح المنظمة التي تسهم في تحقيق جميع المتطلبات السابق ذكرها. من خلال ما تقدم من متطلبات تتضمن تحقيق الجامعة كمنظمة بارعة وتتفاعل هذه المتطلبات وتتكامل مع بعضها لتحقق منظومة البراعة، ولكل جامعة لها أولوياتها ومتطلباتها الخاصة بها وتختلف من جامعة لأخري ومنها وجود رؤية شاملة ومتطورة، وهيكل تنظيمي مناسب يسمح بالتطوير، بناء استراتيجية وفق رؤية ورسالة واضحة، وقيادة فعالة ذات إبداع وابتكار، وقوي بشرية تؤمن بالتطلع للمستقبل ذات مهارات وقدرات عالية تصل بالجامعة إلي أن تكون منظومة بارعة. ومن ثم يتضح بأن الجامعات البارعة هي التي تفي بهذه المتطلبات وقادرة علي تنفيذها حيث تستند إلي مجموعة هن الإجراءات والعمليات التي تساعدها إلي أن تكون جامعة مبدعة ومبتكرة وبارعة وتحقق ميزة تنافسية. 
وه الك مد عة مد الـ صدات والـ ق حات لـ

الم

وفي النهاية يتقدم البحث ببعض التوصيات والمقترحات التي يمكن أن تهه

في تحقيق المنظمة البارعة بالجامعات المصرية وهي كما يلي:

- أن يظهر الاهتمام بالمنظمة البارعة في رؤية الجامعات حتي يمكن تحويل جامعاتنا إلي جامعات بارعة، علي أن يشارك جميع أعضاء المجتمع الجامعي في

$$
\text { وضع هذه الرؤينة. }
$$

- الاهتمام بتنمية القيادات الجامعية لأنها تعد حجر الزاوية الرئيسي في نشر ثقافة المنظمة البارعة داخل الجامعة، عن طريق تنمية مهاراتهم الإدارية وتنمية معارفهم.

- وجود قنوات اتصال فعالة لزيادة التواصل بين قيادات الجامعة والعاملين فيها. - الاستفادة من المنظمات البارعة ومن خبرات بعض الجامعات البارعة في الدول المتقدمة في تحويل جامعاتتا إلي جامعات بارعة دع مراعاتنا لطبيعة الواقع

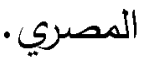
- نشر ثقافة وفلسفة المنظمة البارعة عن طريق عقد الندوات والمؤتمرات التي توضح قيمة المنظمة البارعة والانفتاح علي الأفكار البارعة والمبدعة. - وجود خطة استراتيجية واضحة للجامعات يمكن من خلالها التعرف علي نقاط القوة ومواطن الضعف الداخلية والخارجية، وإشراك أعضاء المجتمع الجامعي في وضع الخطة مما يقلل من مستوي مقاومة التغيير. - تقييم الاحتياجات التدربية لجميع العاملين في الجامعة في ضوه مفاهيم المنظمة البارعة مع وضع جذولة للأولويات في تلبية هذه الاحتياجات. - الاستفادة من الاراسات والأبحاث التي تهاف إلي تحقيق المنظمة البارعة وتسهم في تطوير الجامعات المصرية. 


\section{متطلبات تحقيق المنظمة البارعة بالجامعات المصرية}

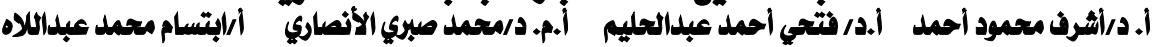

- الاهتمام بالبارعين داخل الجامعة وتحفيزهم وتوفير كافة الإمكانات لهم بما يضمن بقائهم وعدم هجرتهم للخازج. 


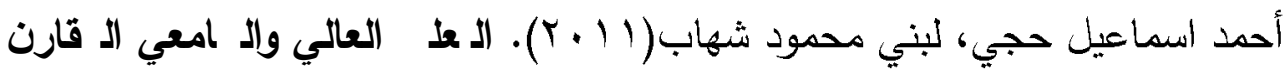

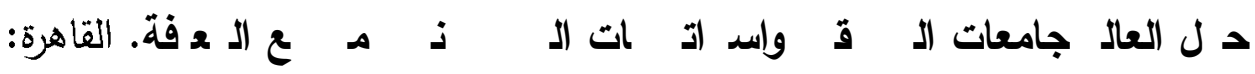

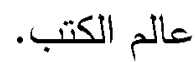

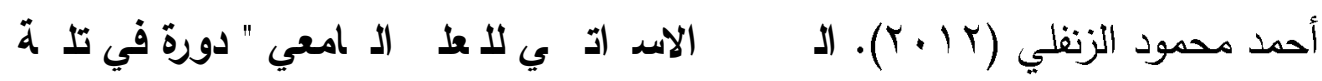

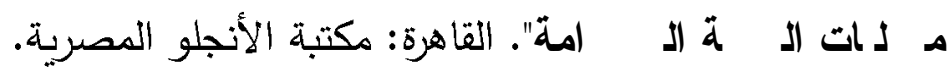

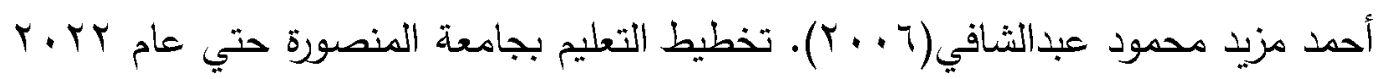

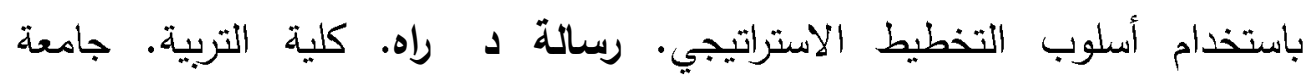
المنصورة.

أثرف محمود أحمد، محم جاد حسين(9 . . ؟). ضد ان ج دة مد سد ات الـ مل العالي في

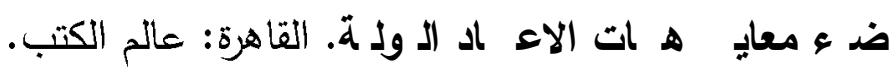

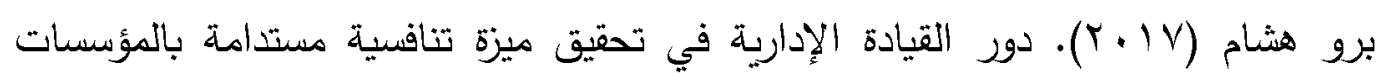

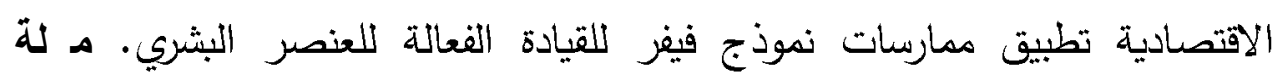
الـ

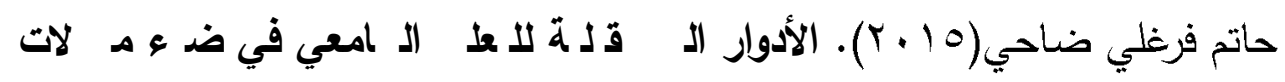
الأل لة الـ الـة القاهرة: الدار العالمية.

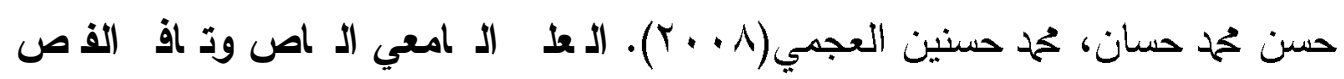
الـ عل الة. القاهرة: دار الجامعة الجديدة.

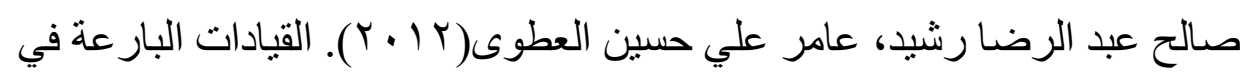
المؤسسات التعليمية الدور التفاعلي للتعقيد السلوكي و التعقيد الثقافي. المؤتمر العلمي الدولي. عولمة الإدارة في عصر المعرفة. جامعة الجنان. طر ابلس- لبنان. ا ــــ.

$$
1 Y / 1 V_{-} 10
$$

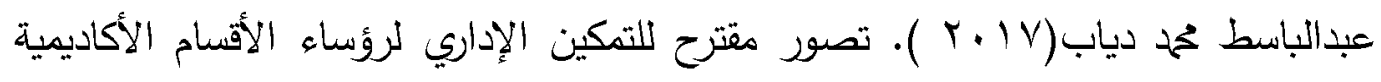
بالجامعات المصرية ودوره في تحفيز الإبداع الإداري لديهج: (جامعة سوهاج نموذجا).

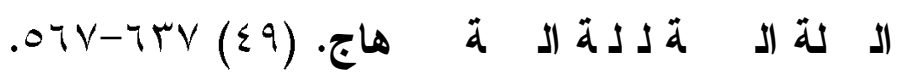




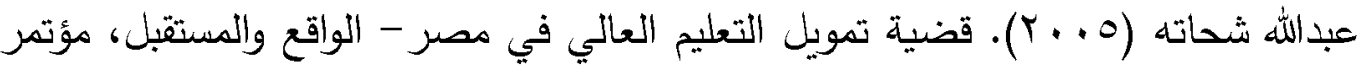

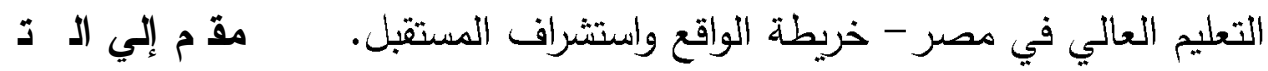
الـ الـ الـ

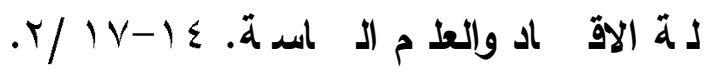
عبير همام بدراوي (10 ب). تطوير التخطيط الاستراتيجي في كليات التربية بالجامعات التهات

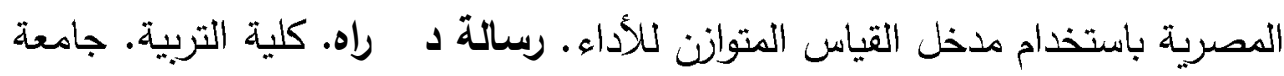

$$
\text { بني سويف. }
$$

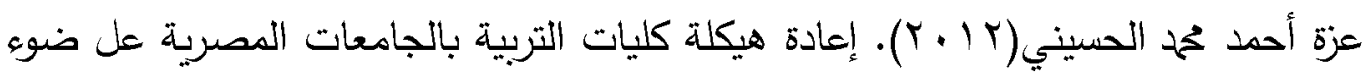

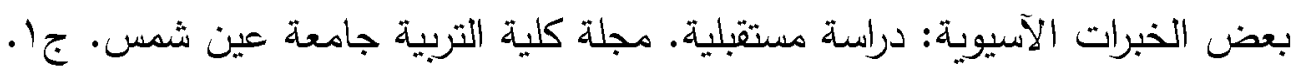

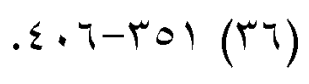

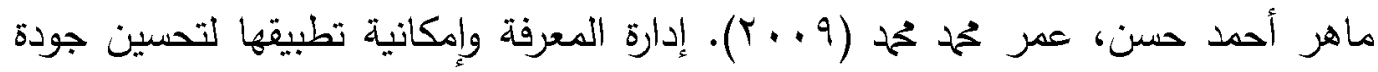

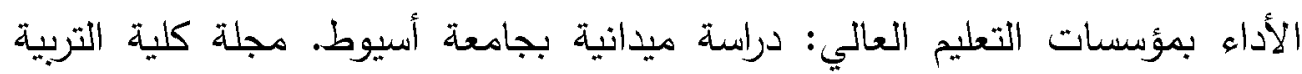

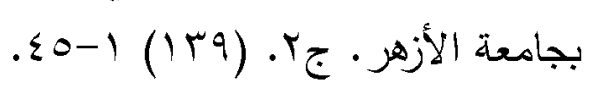

منير محح بدوي(0. . ب). دور الجامعة بين تحديات الواقع وآفاق المستقبل- رؤية نظرية.

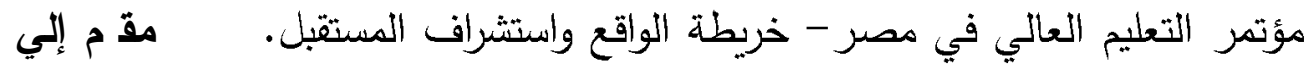
الل ت الل الـ الـ

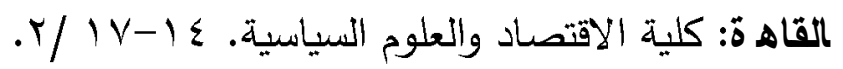

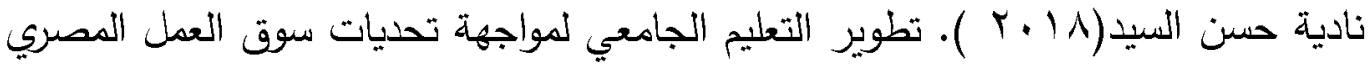

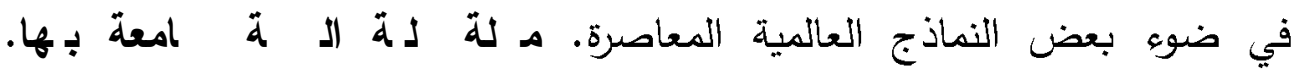
rr $4-Y 1 \cdot(117)$ rq

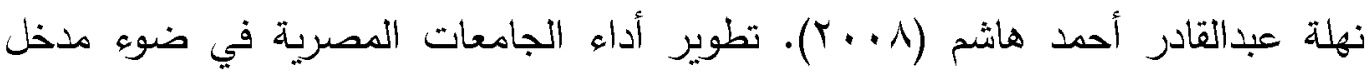
إدارة الجودة الثاملة. القاهرة. مـ لة الإلة الإدارة الل

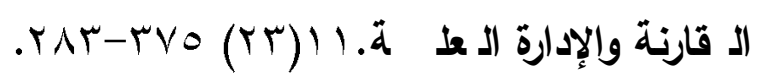

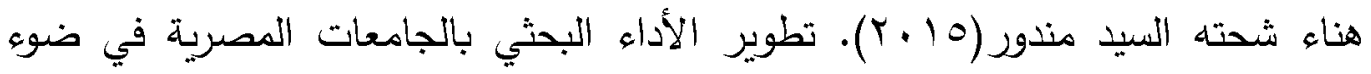

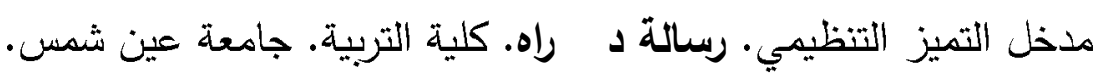




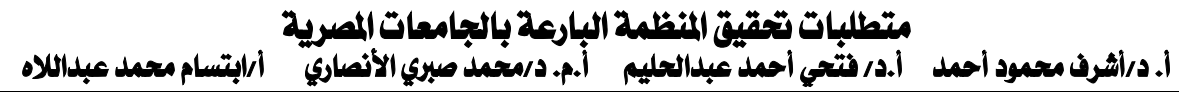

وفاء عياد علي( r ( r ) ). متطلبات التمكين الإداري للقيادات الجامعية بكليات التربية في

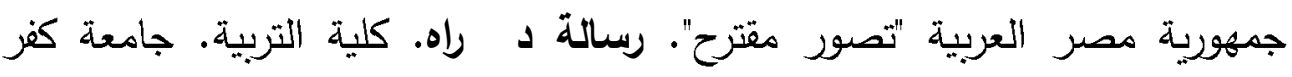
الثيخ.

يوسف حجيم الطائي، عامر عبد كريم الذبحاوي، علي حميد هندي العلي (T 1 Y). التجديد الاستر اتيجي ودوره في تكوين المنظمات البار عة. مجلة القادية للعلوم الإدارية

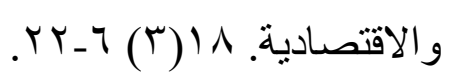

Beer, M., Voelpel, S., Leibold, M. \&Tekie, E. (2005). Strategic Management as Organizational Learning. Developing fit and Alignment through a disciplined Process. Long Range Planning. 5(38)445-465.

Birkinshaw J. \& Gupta, K. (2013). Clarifying the distinctive Contrition of Ambidexterity to the Field of Organization Studies. Academy of Management Perspectives. 4(27)287-298.

Birkinshaw, J. \& Gibson, C. (2004). Building ambidexterity into an organization. MIT Sloan Management Review. 47-55.

Chang, U., Yang, Y., Martin, P., Chi, H. \&Tsai-Lin, T. (2016). Entrepreneurial universities and research ambidexterity. A multilevel analysis. Tech novation.(54)7-21.

Coleman, J. (2015). An Exploration of the role of Leadership Behaviors and Ambidexterity in online Learning Units. Ph.D. The George Washington University. Boston University.

Deem, R., Hillyard, S. \& Reed, M. (2007). Knowledge. higher education and the new managerial-ism. The changing management of UK universities. New York. NY. Oxford University Press.

Duncan, R. (1976). The ambidextrous organization. Designing dual structures for innovation. In: R. H. Kilmann, L. R. Pondy, \& D. Slevin 
(Eds.). The management of organization (167-188). North-Holland. New York.

Edward, K. (2000). International Aspects of Bench marketing, Paper

Presented to the Conference on " Quality Assurance in Higher Education: Standards, Mechanisms and Mutual Recognition", Bangkok, Thailand, 8-10|11, 41-46.

Enger, O., Martinsen, L. \& Tommervik, E. (2015). How Ambidextrous is your Company's Culture? M.A. thesis. Norwegian University of

Science and Technology. Department of Industrial Economics and

Technology Management.

Gschwantner, S.\& Martin, R. (2016). Management Control Systems and Organizational Ambidexterity. Manage Control. (27)371-404.

Kraner, J. (2018). Innovation in high Reliability Ambidextrous

Organizations. Analytical Solutions toward Increasing Innovate Activity. Springer International Publishing A.G: Switzerland.

March, J. (1991).Exploration and Exploitation in Organizational Learning. Organization Science. 2(1)71-87.

MC Donough, E.\& Leifer, R. (1983). Using Simultaneous Structures to cope With uncertainty. the Academy of Management Journal. 4(26)727-735.

O' Reilly, C.A. \& Tushman, M.L. (2010). "The Ambidextrous

Organization". the Ambidextrous Organization- Harvard Business Review.1-6.

O' Reilly, C.A.\& Tushman, M.L. (2013). Organizational Ambidexterity. Past.Present and Future. Academy of Management Perspectives. (11)1-30. 
Raisch, S. \& Birkinshaw, J. (2008). Organizational ambidexterity. Antecedents, outcomes. and moderators. Journal of Management. 34(3)375-409.

Raisch, S. \& Birkinshaw, J. (2008). Organizational ambidexterity. Antecedents, outcomes. and moderators. Journal of Management. 34(3)375-409.

Reynolds, H.(2014). Organizational Ambidexterity at Department Level. PH.D. College of Management and Technology. Wallden University. Rialti, R., Marzi, G., Silic, M. \& Ciappei, C. (2018). "Ambidextrous Organization and agility in big data era. The role of business Process Management Systems" Business Process Management Journal.24(5) 1091-1109.

Zacher, H. \& Wilden, R. (2014). Adaily dairy Study on Ambidextrous Leadership and Self- Reported Employee innovation. Journal of Occupational and Organizational Phycology 4(87)813-820.

Zacher, H.\& Rosing, K. (2015). Ambidextrous Leadership and Team Innovation. Leadership Organization. Development Journal. 56 (1)5468. 